\title{
SSynthesis
}

International Scientific Conference of IT and Business-Related Research

\section{PROCENA ZADOVOLJSTVA STUDENATA PREDAVANJEM KORIŠĆENJEM METODA MAŠINSKOG UČENJA}

\section{DETERMINING STUDENT SATISFACTION WITH A LECTURE USING MACHINE LEARNING METHODS}

\author{
Ana Uzelac ${ }^{1}$, Snežana Mladenović ${ }^{1}$, Dragan Zoranović ${ }^{2}$, Stefan Zdravković ${ }^{1}$, Slađana Janković \\ ${ }^{1}$ Univerzitet u Beogradu, Saobraćajni fakultet, Vojvode Stepe 305, Beograd, Srbija \\ ${ }^{2}$ Univerzitet u Beogradu, Fakultet organizacinih nauka, Jove Ilića 154, Beograd, Srbija
}

\begin{abstract}
Apstrakt:
Predavači se svakodnevno suočavaju sa problemom efikasnog prezentovanja materije. Prilikom procene koliko je predavanje u datom trenutku uspešno, predavači se mogu osloniti jedino na svoje iskustvo koje često može odudarati od realnosti. Zbog usredsređenosti na predavanje, predavač nije u mogućnosti da pravovremeno primeti da li je u učionici npr. postalo pretoplo ili zagušljivo, što može nepovoljno da utiče na sposobnost studenata da prate predavanje. Kad bi predavač u svakom trenutku imao objektivniju informaciju o tome da li su studenti zadovoljni, mogao bi je iskoristiti i prilagoditi svoje predavanje i parametre fizičke sredine njihovim potrebama. Ovaj rad ispituje parametre fizičkog okruženja i predavačevog ponašanja koji utiču na zadovoljstvo studenata predavanjem. Izdvojeni su samo oni parametri koji se mogu meriti korišćenjem Interneta inteligentnih uređaja, a analizirani su korišćenjem metoda mašinskog učenja. Cilj je bio da se izdvoje relevantni parametri, a potom da se odabere metoda mašinskog učenja koja daje najbolje rezultate. Ispitano je deset poznatih klasifikatora i njihova sposobnost da na osnovu posmatranih parametara za dati segment predavanja odrede da li pripada klasi u kojoj su studenti zadovoljni predavanjem ili klasi u kojoj nisu zadovoljni. Od ispitanih algoritama, najbolje rezultate imao je Rotation Forest (75.32\%), a najslabije Ridor algoritam (70.13\%).
\end{abstract}

\section{Ključne reči:}

mašinsko učenje, Internet inteligentnih uređaja, veštačka inteligencija.

\section{Abstract:}

Lecturers regularly face the issue of efficiently presenting some teaching unit. When determining if their presentation is currently successful, lecturers can only rely on their experience which quite often differs from reality. As lecturers are primarily focused on a lecture, they are not able to timely notice if it is too hot or stuffy in the classroom, which may adversely affect the student's ability to actively attend the lecture. If the lecturer had the more objective information about students' satisfaction, he/she could use it to adapt the lecture and adjust the parameters of the physical environment to their needs. This paper analyses the parameters of physical environment and lecturer's behaviour that may affect students' satisfaction with a lecture. We have selected only those parameters that can be measured by means of Internet of things and analyzed them using the machine learning methods. The aim was to select relevant parameters and choose the most efficient and accurate machine learning method. Ten well-known classifiers were examined and their ability to correctly determine if it belongs to the class in which students are satisfied with the lecture or the other one. Rotation Forest algorithm demonstrated the best (75.32\%), while Ridor algorithm (70.13\%) the weakest accuracy (70.13\%) among the tested classifiers.

\section{Key words:}

machine learning, Internet of things, artificial intelligence.

\section{Zahvalnica:}

Zahvaljujemo se Ministarstvu prosvete, nauke i tehnološkog razvoja Republike Srbije, koje je podržalo ovaj rad u okviru projekta pod brojem 036012

\section{UVOD}

Predavač ne može objektivno da odgovori da li je u datom trenutku predavanje dobro ili nije, pogotovo u slučaju kada je auditorijum veliki pa nije moguće pratiti pojedinačne reakcije studenata. Kada bi predavači znali potrebe studenata, bili bi u mogućnosti da prilagode svoje ponašanje i prezentaciju kako bi zadovoljili njihova očekivanja. Ako bi predavač pravovremeno znao da studenti postaju nezadovoljni predavanjem, tu informaciju bi blagovremeno mogao da iskoristi tako što bi promenio svoj stil predavanja, otvorio prozor, uključio grejanje, itd., u zavisnosti od toga šta mu je u datom trenutku sistem koji ispituje zadovoljstvo studenata predložio da uradi.

U cilju unapređenja nastave na Saobraćajnom fakultetu na predmetima koji se predaju u okviru uže naučne oblasti Informatika, sprovedeno je istraživanje koje je za cilj imalo da ispita da li je moguće iskoristiti metode mašinskog učenja za analizu parametara fizičkog okruženja i parametara dobijenih iz preda- vačevog ponašanja kako bi se istrenirao klasifikator koji bi mogao u svakom trenutku da odgovori da li je student zadovoljan tekućim predavanjem.

Istraživanje se zasniva na metodama mašinskog učenja. Mašinsko učenje predstavlja oblast veštačke inteligencije koja se koristi prilikom izgradnje računarskih sistema koji su sposobni da poboljšaju svoje performanse koristeći informacije iz iskustva. Mašinsko učenje svakim danom nalazi sve više primena, a koristi se prilikom odobravanja kredita, klasifikacije dokumenata, u medicini za dijagnostikovanje raznih bolesti, prepoznavanje objekata, itd. Jedan od najčešćih problema koji se rešava je problem klasifikacije nepoznatih instanci u jednu od unapred predefinisanih klasa.

Pored metoda mašinskog učenja, ovaj rad se zasniva na konceptu Interneta inteligentnih uređaja (IoT). Koncept IoT je relativno nov i zbog toga ovom polju trenutno nedostaju standardni i jednoznačne definicije. Jedna od organizacija koja se bavi standardizacijom na polju telekomunikacija, informacija i komunikacionih tehnologija je International Telecommunicati- 
on Union (ITU) koja posmatra IoT kao povezanost u bilo kom trenutku, na bilo kom mestu, bilo čega (ITU, 2005). Kada se govori o dimenziji „bilo čega“, misli se na „pametne stvari” koje mogu biti iz fizičkog ili virtuelnog sveta, a poseduju sposobnost da budu identifikovane i integrisane u komunikacione mreže (ITU-T, 2015).

Naredne sekcije rada organizovane su na sledeći način: u drugoj sekciji će biti pregled literature. Opis istraživanja je dat u trećoj sekciji, a rezultati i diskusija se nalaze u četvrtoj sekciji. U poslednjoj sekciji je dat zaključak.

\section{PREGLED LITERATURE}

Iako postoji veliki broj radova u kojima se koriste metode mašinskog učenja, kao i sve veći broj istraživanja koja se zasnivaju na IoT konceptu, u ovom trenutku ne postoji puno studija koje objedinjuju ova dva koncepta. U jednom od radova koji je u uskoj vezi sa ovim istraživanjem je predstavljen sistem koji u gotovo realnom vremenu sa tačnošću od $80 \%$ može da odredi stepen zainteresovanosti studenata (Gligoric et al., in press). U istraživanju je korišćena kamera i širokopojasni mikrofon za posmatranje ponašanja studenata kako bi se pronašli obrasci koji se mogu koristiti za određivanje stepena zainteresovanosti studenata. U radu je korišćen i pametni telefon sa ugrađenim trokoordinatnim akcelerometrom koji je bio smešten u predavačev džep sa ciljem da meri aktivnost predavača. Sistem je implementiran u Matlabu, a zasniva se na algoritmima mašinskog učenja. Cilj pomenutog istraživanja je bio da posmatra studente i njihove aktivnosti, dok je u ovom radu fokus na ispitivanju parametara fizičkog okruženja i ponašanju predavača.

U fizičkom okruženju postoji veliki broj parametara koji se mogu meriti i analizirati. Prvi zadatak je bio da od velikog skupa parametara izaberemo one koji bi mogli uticati na proces usvajanja znanja, a koji bi se mogli jednostavno meriti korišćenjem "pametnih stvari”. U literaturi postoji veliki broj istraživanja koja potvrđuju negativan uticaj neadekvatnih temperatura na performanse studenata (Pepler \& Warner, 1968; Wyon, 1970; Schoer \& Shaffran, 1973; Wargocki \& Wyon, 2007). Postoji i veliki broj eksperimenata koji potvrđuju da velike količine ugljen-dioskida nepovoljno utiču na performanse studenata (Shaughnessy et al., 2006; Wargocki \& Wyon, 2007; Coley et al., 2007; Bakó-Biró et al., 2012; Ito et al., 2006; Murakami et al., 2006; Molhave, 1986; Otto et al., 1992). Jedan broj radova se bavi ispitivanjem buke i njenih efekata na akademske performanse studenata i saglasni su da buka loše utiče na proces usvajanja znanja (Crook, \& Langdon, 1974; Johnson, 2001; Downs \& Crum, 1978; Bronzaft \& McCarthy, 1975; Evans \& Maxwell, 1997; Kyzar, 1977). Ostalim parametrima je pokazano da povećana vlažnost zajedno sa niskim vazdušnim pritiskom ima negativan efekat na koncentraciju (Howarth \& Hoffman, 1984).

Pored parametara fizičkog okruženja, zadatak je bio da se proučava i predavačevo ponašanje, jer putem ekspresivnog ponašanja predavač može da utiče na zadovoljstvo studenata predavanjem, a samim tim i na sam proces učenja (Murray, 1997). Predavač može da iskaže ekspresivno ponašanje na različite načine: izrazima lica, držanjem tela, tonom glasa (Ambady \& Rosenthal, 1992). Postoje brojna istraživanja koja su potvrdila da analizom različitih vokalnih karakteristika kao što su visina tona, ritam, energija, brzina govora, intonacija, perceptivna glasnost i kvalitet glasa, možemo dobiti informaciju o govornikovom emotivnom stanju (Fairbanks \& Pronovost 1939; Williams \& Stevens 1981; Huber et al., 2000; Batliner et al., 2003; Lee \& Narayanan, 2002) koje s druge strane može da utiče na angažovanje studenata tokom predavanja i njihov uspeh u učionici (Zembylas \& Schutz, 2009).

\section{OPIS ISTRAŽIVANJA}

S obzirom na gore navedeno razmatranje, kao potencijalne parametre iz fizičkog okruženja koji mogu da utiču na zadovoljstvo studenata tokom predavanja izdvojili smo temperaturu, količinu ugljen-dioksida, vlažnost vazduha, vazdušni pritisak i buku. Svaki od ovih parametara je moguće meriti odgovarajućim senzorom, a izmerene vrednosti se mogu odmah poslati na server i obrađivati.

U literaturi je prikazano da glas predstavlja značajan kanal za pokazivanje ekspresivnog ponašanja, a da je broj karakteristika koje se iz njega mogu ekstrahovati ogroman. Odlučili smo se da koristimo skup glasovnih karakteristika koji se pokazao uspešnim u različitim kontekstima (Pentland, 2006).

Eksperimentalni deo istraživanja je sproveden za vreme održavanja vežbi i predavanja na časovima koje je držalo nastavno osoblje angažovano na predmetima uže naučne oblasti Informatika. Za potrebe istraživanja je snimljeno 10 predavanja, a svakom predavanju je prisustvovalo između 10 i 20 studenata.

Za snimanje parametara fizičkog okruženja i glasa korišćeni su sledeći uređaji:

- tablet opremljen senzorom za buku koji je bio lociran u sredini učionice i korišćen za detekciju nivoa buke,

- ploča sa senzorima na kojoj su se nalazili senzori za merenje količine ugljen-dioksida, temperature, vlažnosti vazduha i vazdušnog pritiska,

- Bluetooth headset povezan sa računarom koji se koristio za snimanje predavačevog glasa, a zvuk je sniman na frekvenciji od $8 \mathrm{kHz}$.

Pre samog procesa snimanja, vremena na svim uređajima su bila sinhronizovana. Dok su uređaji merili i snimali parametre iz okruženja, zadatak studenata je bio da tokom samog predavanja označe delove predavanja kojima su zadovoljni kao i delove kojima nisu. To su radili pritiskanjem jednog od dva dugmeta na veb-stranici, pri čemu pritiskanje prvog dugmeta znači da su zadovoljni, a pritiskanje drugog da nisu. Segmentacija je rađena na intervalima dužine od 30 sekundi.

Skup podataka za treniranje je napravljen korišćenjem sledećih ograničenja:

- segmenti sa više od $80 \%$ negativnih glasova su markirani kao "nezadovoljni",

- sagmenti sa više od $80 \%$ pozitivnih glasova su označeni kao "zadovoljni”,

- segmenti sa manje od $80 \%$ bilo pozitivnih bilo negativnih glasova su odbačeni,

- ako je student na jednom segmentu glasao više puta, ti glasovi su odbačeni,

- odbačeni su i segmenti na kojima je bilo dosta šuma.

Inicijalno je dobijeno 7.5 sati materijala, a posle primene ovih ograničenja ostao je 231 segment dužine 30 sekundi.

\section{REZULTATI ISTRAŽIVANJA I DISKUSIJA}

Nakon završenih predavanja, rađena je analiza i obrada snimljenih podataka. Senzori za merenje količine ugljen-dioksida, temperature, vlažnosti vazduha i vazdušnog pritiska su registrovali jednu vrednost na svakih 30 sekundi i tu vrednost slali na server zajedno sa vremenom merenja. Što se buke tiče, ona je uzorkovana svake sekunde pomoću senzora za nivo buke koji je bio ugrađen u tablet, a na samom tabletu je čuvan csv (commaseparated values) fajl sa vremenima uzorkovanja i izmerenim vrednostima. Za svaki segment su potom urađene sledeće statističke analize koje se odnose na buku: 
1. srednja vrednost,

2. srednja vrednost apsolutnih devijacija,

3. suma kvadrata devijacija,

4. medijana $\mathrm{i}$

5. standardna devijacija.

Ekstrakcija glasovnih karakteristika je urađena korišćenjem toolboxa koji je razvijen od strane Human Dynamics grupe (Pentland, 2006), i kao rezultat ekstrakcije dobijene su 22 glasovne karakteristike:

1. srednja vrednost formantne frekvencije,

2. srednja vrednost sigurnosti formantne frekvencije,

3. srednja vrednost spektralne entropije,

4. srednja vrednost najvećeg autokorelacionog vrha,

5. srednja vrednost lokacije najvećeg autokorelacionog vrha,

6. srednja vrednost ukupnog broja autokorelacionih vrhova,

7. srednja vrednost energije u frejmu,

8. srednja vrednost promene energije u vremenu,

9. standardna devijacija formantne frekvencije,

10. standardna devijacija sigurnosti u formantnu frekvenciju,

11. standardna devijacija spektralne entropije,

12. standardna devijacija vrednosti najvećeg autokorelacionog vrha,

13. standardna devijacija lokacije autokorelacionog vrha,

14. standardna devijacija broja korelacionih vrhova,

15. standardna devijacija energije $\mathrm{u}$ frejmu,

16. standardna devijacija promene energije u vremenu,

17. prosečna dužina glasovnih segmenata,

18. prosečna dužina govornih segmenata,

19. procenat vremena govora,

20. stopa govora,

21. deo vremena u kom se priča i

22. prosečan broj kratkih govornih segmenata.

Nakon ovog postupka dobijen je skup podataka za treniranje koji je imao 231 instancu, a svaka instanca 31 atribut. Visoka dimenzionalnost podataka nosi sa sobom dosta problema, pa je poželjno da bude smanjena tako što će se odabrati podskup relevantnih atributa putem metode koja se zove selekcija atributa.

Svi atributi mogu biti klasifikovani u jednu od četiri disjunktne klase (Novaković, 2013):

- irelevantni atributi,

- slabo relevantni redundantni atributi,

- slabo relevantni neredundantni atributi,

- jako relevantni atributi.

Optimanalni skup atributa za učenje čine slabo relevantni neredundantni atributi i jako relevantni atributi.

Da bismo odrediti skup atributa koji su redundantni ili irelevantni koristili smo statističku vrednost koja se zove informacijski dobitak (Information Gain). Informacijski dobitak spada u kvantitativne mere kojom se računa vrednost atributa i predstavlja očekivanu redukciju entorpije uzrokovanu razdvajanjem primera na osnovu tog atributa (Witten, Frank, \& Hall, 2011). Može se računati korišćenjem sledeće formule:

$$
\begin{aligned}
& \text { InfoGain(Class,Attribute })=\mathrm{H}(\text { Class })-\mathrm{H} \text { (Class } \mid \text { Attribute }) \\
& \text { gde } \mathrm{H} \text { predstavlja entropiju. }
\end{aligned}
$$

Informacijski dobitak smo računali korišćenjem Wekinog (Hall et al., 2009) evaluatora InfoGainAttributeEval koristeći podrazumevane vrednosti. Kao što je bilo očekivano, za veliki broj atributa smo dobili da imaju vrednost nula, što znači da su irelevantni ili redundantni. Za samo osam atributa je informacijski dobitak bio veći od nule i oni su prikazani u Tabeli 1 .

\begin{tabular}{lc}
\hline Atribut & $\begin{array}{c}\text { Vred- } \\
\text { nost } \\
\text { atributa }\end{array}$ \\
\hline Količina ugljen-dioksida & 0,2015 \\
\hline Vlažnost vazduha & 0,1312 \\
\hline Standardna devijacija energije u frejmu & 0,0848 \\
\hline Srednja vrednost energije u frejmu & 0,0709 \\
\hline Standardna devijacija promene energije u vremenu & 0,0663 \\
\hline Standardna devijacija broja korelacionih vrhova & 0,0658 \\
\hline Vazdušni pritisak & 0,0601 \\
\hline Temperatura & 0,0369 \\
\hline
\end{tabular}

Tabela 1. Atributi i njihove vrednosti

Iz tabele se vidi da je jedan od najbitnijih faktora za zadovoljstvo studenata količina ugljen-dioksida, a za njom odmah sledi vlažnost vazduha. Od parametara fizičkog okruženja još su se vazdušni pritisak i temperatura pokazale kao bitne. Energija u frejmu predstavlja jačinu glasa na datom segmetu i označava nivo konverzacione aktivnosti predavača. Njena srednja vrednost, standardna devijacija, kao i standardna devijacija njenih promena $\mathrm{u}$ jedinici vremena se pokazalo bitnim pri određivanju zadovoljstva studenata. Pored ove dve glasovne karakteristike, utvrđeno je i da standardna devijacija broja korelacionih vrhova ima uticaja, najverovatnije iz razloga što se iz nje može odrediti da li je u datom frejmu prisutan glas.

Skup podataka za treniranje je dobijen odbacivanjem nerelevantnih atributa. Dakle, skup za treniranje se sastoji od 231 instance od kojih svaka ima osam atributa. Dobijeni skup za treniranje se sastoji od 157 instanci (68\%) koje su studenti označili kao segmente na kojima su bili zadovoljni predavanjem i 74 instance (32\%) koje su bile označene kao segmenti predavanja na kojima studenti nisu bili zadovoljni.

$\mathrm{Na}$ ovakvom skupu podataka je urađena evaluacija performansi izabranog skupa klasifikatora. Testirana je njihova mogućnost da uspešno odrede da li će instanca koju predstavlja sekvenca od 30 sekundi nekog predavanja biti uspešno klasifikovana u odgovarajuću klasu. Za ovo je korišćen Weka toolkit (Hall et al., 2009) i desetostruka unakrsna validacija. Za unakrsnu validaciju je karakteristično da se radi višestruko ponavljanje procesa evaluacije na testnom skupu pri čemu se koriste različiti slučajno izabrani skupovi za učenje i testiranje. Pri svakoj iteraciji se radi odgovarajuća zamena skupa podataka za učenje i testnog skupa (Kohavi, 1995). U slučaju k-struke unakrsne validacije, najpre se inicijalni skup instanci slučajnim izborom podeli u k međusobno različitih particija približno iste veličine. Postupak je iterativan s tim da se u jednoj iteraciji k-1 particija koristi kao skup za učenje, a konstruisani model se testira na preostaloj particiji koja predstavlja testni skup. Postupak se ponavlja k puta, tako da je svaka od particija po jednom u ulozi testnog skupa instanci. Ocenu stvarne frekvencije grešaka klasifikacijskog modela predstavlja prosečna frekvencija grešaka svih $\mathrm{k}$ iteracija postupka. U praksi se najčešće koristi stratifikovana petostruka ili desetostruka unakrsna validacija, jer se pokazala kao dovoljno tačna, a nije računarski prezahtevna (Novaković, 2013).

Za merenje performansi klasifikatora korišćeni su sledeći parametri:

- Tačnost,

- Procenat stvarno pozitivnih - za zadovoljne i nezadovoljne segmente (TP), 


\begin{tabular}{lcccccccc}
\hline \multicolumn{1}{c}{ Algoritam } & Tačnost (\%) & TP (Z) & FP (Z) & Preciznost (Z) & TP (NZ) & FP (NZ) & Preciznost (NS) & Kappa \\
\hline Rotation Forest (Rodriguez et al., 2006) & 75,3247 & 0,873 & 0,5 & 0,787 & 0,5 & 0,127 & 0,649 & 0,3967 \\
\hline Alternating Decision Tree (Freund \& Mason, 1999) & 74,8918 & 0,834 & 0,432 & 0,804 & 0,568 & 0,166 & 0,618 & 0,4108 \\
\hline J48 (Bhargava et al, 2013) & 73,593 & 0,834 & 0,473 & 0,789 & 0,527 & 0,024 & 0,6 & 0,3734 \\
\hline BFTree (Shi, 2007) & 73,160 & 0,834 & 0,486 & 0,784 & 0,514 & 0,166 & 0,594 & 0,3608 \\
\hline Random Forest (Breiman, 2001) & 72,727 & 0,854 & 0,541 & 0,77 & 0,459 & 0,146 & 0,596 & 0,3332 \\
\hline MultiBoostAB (Webb, 2000) & 72,727 & 0,917 & 0,676 & 0,742 & 0,324 & 0,083 & 0,649 & 0,2783 \\
\hline BayesNet & 72,294 & 0,675 & 0,176 & 0,891 & 0,824 & 0,325 & 0,545 & 0,4398 \\
\hline NN1 (Martin, 1995) & 70,130 & 0,764 & 0,432 & 0,789 & 0,568 & 0,236 & 0,532 & 0,3261 \\
\hline AdaBoostM1 (Freund, \& Schapire, 1996) & 70,996 & 0,866 & 0,622 & 0,747 & 0,378 & 0,134 & 0,571 & 0,2686 \\
\hline Ridor (Gaines \& Compton, 1995) & 70,130 & 0,796 & 0,5 & 0,772 & 0,5 & 0,204 & 0,536 & 0,3016 \\
\hline
\end{tabular}

TP - procenat stvarno pozitivnih; FP - lažno pozitivna stopa; Z - segmenti gde su studenti zadovoljni predavanjem; NZ - segmenti gde studenti nisu bili zadovoljni predavanjem.

Tabela 2. Lista evaluiranih klasifikatora

- Procenat lažno pozitivnih - za zadovoljne i nezadovoljne segmente (FP),

- Preciznost,

- Kappa statistika (predstavlja meru predviđanja saglasnosti za dva različita ocenjivača) (Vieira \& Kaymak, 2010).

Svaki klasifikator je testiran korišćenjem istog skupa podataka za učenje koji je predstavljao ulaz u Weka alat. Svi ispitivani algoritmi su pokazali tačnost veću od $70 \%$. Najveću tačnost je pokazao Rotation Forest algoritam $(75,3247 \%)$ čija Kappa statistika je iznosila 0,3967. Nešto slabiju tačnost je pokazao Alternating Decision Tree algoritam $(74,8918 \%)$, ali je vrednost njegove Kappa statistike bila bolja $(0,4108)$, pa bi prilikom odabira algoritma za rešavanje ovog problema oba algoritma trebalo razmatrati. Najslabiju tačnost su pokazali AdaBoostM1 i Ridor algoritam čije su tačnosti respektivno 70,9957\% i 70,1299\%.

Kompletna lista evaluiranih klasifikatora sa postignutim tačnostima data je u Tabeli 2 .

\section{ZAKLJUČAK}

U ovom istraživanju se ispituje mogućnost korišćenja metoda mašinskog učenja i Interneta inteligentnih uređaja sa ciljem da se utvrdi zadovoljstvo studenata predavanjem. Merili smo pet parametara fizičkog okruženja: temperaturu, vlažnost vazduha, količinu ugljen-dioksida, vazdušni pritisak i buku. Svaki od tih parametara izuzev buke se pokazao relevantnim prilikom određivanja zadovoljstva studenata. Pored parametara fizičkog okruženja, ekstrahovane su i ispitivane karakteristike zvučnog signala. Izdvojene su 22 glasovne karakteristike i usvojene su četiri koje su se pokazale bitnim, a to su:

1. Standardna devijacija energije u frejmu,

2. Srednja vrednost energije u frejmu,

3. Standardna devijacija promene energije u vremenu i

4. Standardna devijacija broja korelacionih vrhova.

Pored toga, u radu se ispituju performanse 10 različitih algoritama za mašinsko učenje i njihova mogućnost da tačno razvrstaju instancu predavanja. Najbolje performanse su postigli Rotation Forest $(75,3247 \%)$ i Alternating Decision Tree $(74,8918 \%)$.

Rezultati istraživanja pokazuju da se metode mašinskog učenja mogu koristiti prilikom određivanja zadovoljstva studenata predavanjem. Ovo istraživanje predstavlja osnovu za kasniju implementaciju sistema koji bi imao mogućnost da automatski odredi zadovoljstvo pohađalaca nekog predavanja i da generiše određene preporuke predavačima. Rezultati mogu da predstavljaju osnovu nekog opštijeg sistema koji bi bio u mogućnosti da vrši automatsku optimizaciju prostora za učenje korišćenjem aktuatora.

\section{LITERATURA}

Ambady, N., \& Rosenthal, R. (1992). Thin slices of expressive behavior as predictors of interpersonal consegments: A metaanalysis. Psychological Bulletin. 111 (2), pp. 256-274.

Bakó-Biró, Z., Clements-Croome, D. J., Kochhar, N., Awbi, H. B., \& Williams, M. J. (2012). Ventilation rates in schools and pupils' performance. Building and Environment. 48, pp. 215-223.

Batliner, A., Fischer, K., Huber, R., Spilker, J., \& Noth, E. (2003). How to find trouble in communication. Speech Communication. 40(1), pp. 117-143.

Bhargava, N.G.S., Bhargava, R., \& Mathuria, M. (2013). Decision Tree Analysis on 48 Algorithm for Data Mining. International Journal of Advanced Research in Computer Science and Software Engineering. 3 (6), pp. 1114-1119.

Breiman, L. (2001). Random Forests. Machine Learning. 45 (1), pp. 5-32.

Bronzaft, A.L., \& McCarthy, D.P. (1975). The effect of elevated train noise on reading ability. Environment and Behaviour. 7(4), pp. 517-527.

Coley, D.A., Greeves R., \& Saxby B.K. (2007). The Effect of Low Ventilation Rates on the Cognitive Function of a Primary School Class, The International Journal of Ventilation. 6(2), pp. 107-112.

Crook, M.A., \& Langdon, F.J. (1974). The effects of aircraft noise in schools around London Airport. Journal of Sound and Vibration. 34 (2), pp. 221-232.

Downs, D., \& Crum, M. (1978). Processing demands during auditory learning under degraded listening conditions. Journal of Speech and Hearing Research. 21, pp. 702-714.

Evans, G.W., \& Maxwell L. (1997). Chronic noise exposure and reading deficits: the mediating effects of language acquisition. Environment and Behaviour. 29(5), pp. 638-657.

Fairbanks, G., \& Pronovost, W. (1939). An experimental study of the pitch characteristics of the voice during the expression of emotions. Speech Monographs. 6, pp. 87-104.

Freund, Y., \& Mason, L. (1999). The Alternating Decision Tree Algorithm. In Proceedings of the 16th International Con- 
ference on Machine Learning. June 27-30 (pp. 124-133). Bled, Slovenia: Morgan Kaufmann Publishers.

Freund, Y., \& Schapire, R. (1996). Experiments with a new boosting algorithm. In Proceedings of the 13th International Conference on Machine Learning. July 3-6 (pp. 148-156). Bari, Italy: Morgan Kaufmann Publishers.

Gaines, B.R., \& Compton, P. (1995). Induction of Ripple-Down Rules Applied to Modeling Large Databases. Journal of Intelligent Information Systems. 5(3), 211-228.

Gligoric, N., Uzelac, A., Krco, S., Kovacevic, I., \& Nikodijevic, A. (in press). Smart Classroom System for Detecting Level of Interest a Lecture Creates in a Classroom. Journal of Ambient Intelligence and Smart Environments, ISSN 1876-1364.

Hall, M., Frank, E., Holmes, G., Pfahringer, B., Reutemann P., \& Witten, I.H. (2009). The WEKA Data Mining Software: An Update, ACM SIGKDD Explorations Newsletter. 1(1),10-18.

Howarth, E., \& Hoffman, M.S. (1984). A Multidimensional Approach to the Relationship between Mood and Weather. British Journal of Psychology, 75, 15-23.

Huber, R., Batliner, A., Buckow, J., Noth, E, Warnke, V., \& Niemann, H. (2000). Recognition of Emotion in realistic dialog scenario. In Proceedings of the International Conference Spoken Language Processing. October 16-20 (pp. 665-668). Beijing, P. R. China.

Ito, K., Murakami, S., Kaneko, T., \& Fukao H. (2006). Study on the productivity in the classroom (part 2): realistic simulation experiment on effects of air quality/thermal environment on learning performance. Healthy Buildings, pp. 207212.

ITU (2005). Internet Reports Series, ITU Internet Reports 2005 The Internet of Things. Retrieved 28 February 2015, from http://www.itu.int/osg/spu/publications/internetofthings/.

ITU-T (2012). Telecommunication Standardization Sectof of International Telecomunication Union, Overview of the Internet of things, Recommendation ITU-T Y.2060. Retrieved 5 March 2015, from http://www.itu.int/ITU-T/recommendations/rec.aspx?rec $=y .2060$.

Johnson, E. (2001). Let's hear it for learning: Improving classroom acoustics can maximize student productivity at a minimal cost. American School and University. 73 (11), pp. 28-30.

Kohavi, R. (1995). A study of cross-validation and bootstrap for accuracy estimation and model selection. In Proceedings of the 14th International Joint Conference on Artificial Intelligence. August 20-25 (pp. 1137-1143). Montreal, Quebec, Canada: Morgan Kaufmann Publishers.

Kyzar, B.L. (1977). Noise Pollutions and Schools: How much is too much? Council of Educational Facilities Planners Journal. 4, pp. 10-11.

Lee, C.M., \& Narayanan, S.S. (2002). Combining acoustic and language information for emotion recognition. In Proceedings of the International Conference on Speech and Language Processing. September 16-20 (pp. 873-876). Denver, Colorado, USA.

Martin, B. (1995). Instance-Based learning: Nearest Neighbor With Generalization. Master thesis. University of Waikato, Hamilton, New Zealand.

Molhave, L., Bach, B., Feddersen, O. F. (1986). Human reactions to low concentrations of volatile organic compounds. Environment International. 12, pp. 167-175.

Murakami, S., Kaneko, T., Ito, K., \& Fukao H. (2006). Study on the productivity in the classroom (part 1) field survey of the effects of air quality/thermal environment on learning performance. Healthy Buildings. pp. 271-276.

Murray, H. G. (1997). Effective teaching behavior in the college classroom. In Raymond P. Perry and John C. Smart, Effective Teaching in Higher Education: Research and Practice (pp. 171-204), New York: Agathon Press.

Novaković, J. (2013). Rešavanje klasifikacionih problema mašinskog učenja. Vrnjačka Banja: Fakultet tehničkih nauka u Čačku, SaTCIP.

Otto, D. A., Hudnell, H.K., House, D.E., \& Molhave, L. (1992). Exposure of humans to a volatile organic mixture. I. Behavioral Assessment. Archives of Environmental Health. 47(1), 23-30.

Pentland, A. (2006). A Computational Model of Social Signaling. In Proceedings of the 18th International Conference on Pattern Recognition. August 20-24 (pp. 1080 - 1083). Hong Kong, China.

Pepler, R.D., \& Warner R.E. (1968). Temperature and learning: an experimental study. ASHRAE Transactions. 74 (2), 211219.

Rodriguez, J.J., Kuncheva, L.I., \& Alonso, C.J. (2006). Rotation Forest: A new classifier ensemble method. IEEE Transactions on Pattern Analysis and Machine Intelligence. 28(10), 1619-1630.

Schoer, L., \& Shaffran, J. (1973). A combined evaluation of three separate research projects on the effects of thermal environment on learning and performance. ASHRAE Transactions. 79 (1), 97-108.

Shaughnessy, R. J., Haverinen-Shaughnessy, U., Nevalainen A., \& Moschandreas, D. (2006). A preliminary study on the association between ventilation rates in classrooms and student performance. Indoor Air. 16 (6), 465-468.

Shi, H. (2007). Best-first decision tree learning. Master thesis. The University of Waikato, Hamilton, New Zeland.

Vieira, S., \& Kaymak, U. (2010). Cohen's Kappa statistic as a performance measure for feature selection. In Proceedings of IEEE International Conference on Fuzzy Systems. July 1823, pp. 1-8, Barcelona.

Wargocki, P., Wyon, D.P. (2007). The effects of moderately raised classroom temperatures and classroom ventilation rate on the performance of schoolwork by children. HVACandR Research. 13(2), 193-220.

Webb, G.I. (2000). MultiBoosting: A Technique for Combining Boosting and Wagging. Machine Learning. 40(2), 159-196.

Williams, C.E., \& Stevens K.N. (1981). Vocal correlates of emotional states. In Darby, J. K. Speech Evaluation in Psychiatry (pp. 221-240). New York: NY Grune and Stratton.

Witten, H., Frank, E., \& Hall, M.A. (2005). Data Mining: Practical Machine Learning Tools and Techniques, Morgan Kaufmann.

Wyon, D.P. (1970). Studies of children under imposed noise and heat stress. Ergonomics. 13(5), 598-612.

Zembylas, M., \& Schutz, P.A. (2009). Research on teachers' emotions in education: Findings, practical implications and future agenda. In P.A. Schutz and M. Zembylas, Advances in teacher emotion research: The impact on teachers' lives (pp. 367-377). New York, NY: Springer. 